IP $\rightleftharpoons$ B

\title{
Descrição do perfil do tronco de árvores em plantios de diferentes espécies por meio de redes neurais artificiais
}

\author{
Bráulio Pizziôlo Furtado Campos ${ }^{1}$, Gilson Fernandes da Silva², Daniel Henrique Breda Binoti ${ }^{2}$, Adriano Ribeiro de Mendonça², \\ Helio Garcia Leite ${ }^{3}$
}

${ }^{1}$ Rod. Mal. Rondon, s/n - Zona Rural, CEP 17120-000, Agudos, SP, Brasil

${ }^{2}$ Universidade Federal do Estado do Espírito Santo, CEP 29550-000, Jerônimo Monteiro, ES, Brasil

${ }^{3}$ Universidade Federal de Viçosa, Avenida P.H. Rolfs, CEP 35760-000, Viçosa, MG, Brasil

"Autor correspondente:
danielhbbinoti@gmail.com

Termos para indexação:

Inventário florestal

Manejo florestal

Inteligência artificial

Index terms:

Forest inventory

Forest management

Artificial intelligence

Histórico do artigo:

Recebido em 09/03/2016

Aprovado em 23/03/2017

Publicado em 30/06/2017

doi: 10.4336/2017.pfb.37.90.1181

\begin{abstract}
Resumo - O objetivo deste trabalho foi analisar a capacidade de uma rede neural artificial (RNA) em descrever o perfil do fuste de árvores de diferentes gêneros e espécies em diferentes condições de crescimento. Para fins comparativos, foram ajustadas equações, empregando-se análise de regressão, para descrever o perfil do tronco. Tanto para as redes neurais quanto para as equações de regressão, a avaliação da acurácia foi realizada com base no coeficiente de correlação entre os diâmetros observados e estimados ao longo do fuste, a raiz quadrada do erro quadrático médio percentual (RMSE) e análise gráfica. Os métodos de inteligência artificial, especialmente RNA, podem ser eficazes em descrever o perfil do fuste de árvores de diferentes espécies em diferentes condições de crescimento, utilizando apenas uma RNA, com eficiência semelhante aos modelos de regressão tradicionalmente empregados por empresas florestais.
\end{abstract}

\section{Stem profile description in plantations for different species using artificial neural network}

\begin{abstract}
The objective of this study was to analyze the ability of an artificial neural network (ANN) to describe the stem profile of trees of different genera and species in different growing conditions. For comparative purposes, equations were fit, using regression analysis to describe the stem profile. For neural network as well as for the regression equations, evaluation of accuracy was based on correlation coefficient between observed and estimated diameters along the stem, square root of the mean square percentage error (RMSE) and graphical analysis. Artificial intelligence methods, especially ANN, can be effective in describing trees bole profile of different species in different growth conditions using only one ANN with similar efficiency as regression models traditionally employed by forestry companies
\end{abstract}

\section{Introdução}

Historicamente, o mercado de madeira sólida no Brasil é abastecido principalmente por produtos de florestas nativas, explorados, na maioria das vezes, de forma irregular. Diante disso, há a necessidade de substituição dessa matéria prima por madeira oriunda de floresta plantada, buscando reduzir o impacto sobre as florestas nativas e garantir o abastecimento constante desse mercado.
Para se ter um produto competitivo neste mercado, é necessário utilizar técnicas para aumentar a produção e a qualidade da madeira dos plantios florestais. Com isso, práticas como desbaste e desrama passaram a ser estudadas e aplicadas em plantios comerciais (Silva, 1970; Soares, 1970; Campos, 1980; Bertolotti et al., 1983; Nogueira et al., 2001, Nogueira, 2003; Dias 2005; Leite et al., 2010; Binoti, 2010). Aliada a estas técnicas de manejo, é indispensável a definição de estratégias 
ótimas para destinação destes produtos, maximizando o retorno econômico do investimento.

Com o intuito de definir estratégias representativas da realidade, convertendo árvores em multiprodutos, com aumento significativo da receita oriunda de um povoamento florestal, é preciso ter informações confiáveis do perfil dos fustes. A precisão das estimativas obtidas para descrever os perfis dos fustes é decisiva para o sucesso de um processo de otimização e tem sido objetivo de vários estudos (Assis et al., 2001; Fischer et al., 2001; Mendonça et al., 2007; Souza et al., 2008; Souza, 2009; Leite et al., 2011; Campos et al., 2013; Môra et al., 2014).

É possível destacar diferentes modelos desenvolvidos buscando melhor desempenho das estimativas obtidas para descrever o perfil do fuste de forma fiel (Kozak et al., 1969; Demaerschalk, 1972; Ormerod, 1973; Max \& Burkhart, 1976; Garay, 1979; Baldwin Júnior \& Feduccia, 1991; Garcia et al., 1993; Leite \& Garcia, 2001; Pires \& Calegário, 2007).

A busca por melhores estimativas direcionam a pesquisa para testes de novas ferramentas e metodologias com o objetivo de descrever o perfil do fuste, como as redes neurais artificiais (RNA), que possuem a capacidade de assimilar e modelar diversas variáveis e suas relações não lineares, com a possibilidade de utilizar variáveis qualitativas e quantitativas para melhor assimilação do conhecimento de forma análoga ao sistema neurobiológico (Haykin, 2001).
A eficiência da aplicação de RNA em plantios florestais vem sendo comprovada por diversos estudos realizados nos últimos anos, principalmente ligados à mensuração florestal. Nesta área podem ser citados os trabalhos sobre estimação de altura (Binoti et al., 2013b), estimação do volume de árvores (Diamantopoulou, 2006; Görgens et al., 2009, 2014; Silva et al., 2009; Diamantopoulou \& Milios, 2010; Binoti et al., 2014), modelagem em nível de povoamento e em nível de árvores individuais (Binoti, 2010), modelagem por classe de diâmetro (Leduc et al., 2001; Binoti et al., 2012; 2013a), modelagem do afilamento do fuste (Diamantopoulou, 2005b; Leite et al., 2011; Soares et al., 2012) e quantificação de casca (Diamantopoulou, 2005a).

Diante do exposto, este trabalho tem por objetivo analisar a capacidade de uma RNA em descrever o perfil do fuste de árvores de diferentes gêneros e espécies, em distintas condições de crescimento.

\section{Material e métodos}

\section{Descrição da área e coleta de dados}

Este estudo foi realizado com dados de uma fazenda na região do Triângulo Mineiro, MG. A área de plantio é de 22.624 ha, sendo 475 ha de Pinus spp. e 22.149 ha de Eucalyptus spp., em diferentes idades, ciclos e espaçamentos de plantio (Tabela 1). Foram utilizados dados de cubagem de 611 árvores-amostra (Tabela 2).

Tabela 1. Proporção da área de plantio de acordo com gênero e classe de idade.

\begin{tabular}{|c|c|c|c|c|c|c|c|c|c|}
\hline \multirow{2}{*}{ Gênero } & & \multicolumn{7}{|c|}{ Classes de idade (anos) } & \multirow{2}{*}{ Total } \\
\hline & & $2,0-3,0$ & $3,0-4,0$ & $4,0-5,0$ & $5,0-6,0$ & $6,0-7,0$ & $7,0-8,0$ & $8,0-9,0$ & \\
\hline \multirow{2}{*}{ Eucalyptus } & Área (ha) & 5.117 & 6.679 & 1.839 & 3.104 & 3.319 & 2.092 & & 22.149 \\
\hline & $\%$ do Total & $23 \%$ & $30 \%$ & $8 \%$ & $14 \%$ & $15 \%$ & $9 \%$ & & $98 \%$ \\
\hline \multirow{2}{*}{ Pinus } & Área (ha) & & & & & & 225 & 250 & 475 \\
\hline & $\%$ do Total & & & & & & $1 \%$ & $1 \%$ & $2 \%$ \\
\hline \multirow{2}{*}{ Total } & Área (ha) & 5.117 & 6.679 & 1.839 & 3.104 & 3.319 & 2.318 & 250 & 22.624 \\
\hline & $\%$ do Total & $23 \%$ & $30 \%$ & $8 \%$ & $14 \%$ & $15 \%$ & $10 \%$ & $1 \%$ & $100 \%$ \\
\hline
\end{tabular}

Tabela 2. Frequência de árvores cubadas por gênero.

\begin{tabular}{ccccccc}
\hline & \multicolumn{4}{c}{ Classe de idade (anos) } & \\
\cline { 2 - 5 } Gênero & $\mathbf{3 , 0}-\mathbf{4 , 0}$ & $\mathbf{4 , 0}-\mathbf{5 , 0}$ & $\mathbf{6 , 0}-\mathbf{7 , 0}$ & $\mathbf{7 , 0}-\mathbf{8 , 0}$ & $\mathbf{8 , 0}-\mathbf{9 , 0}$ & \\
& & & & & & \\
\hline $\begin{array}{c}\text { Eucalyptus } \\
\text { Pinus }\end{array}$ & 292 & 38 & 173 & & & 503 \\
Total & 292 & 38 & 173 & 59 & 49 & 611 \\
\hline
\end{tabular}

Para a cubagem, foram medidas seções a 0,$0 ; 0,3$; 0,$7 ; 1,3 ; 2,0 \mathrm{~m}$ e, após essa altura, a cada $1,0 \mathrm{~m}$ até a altura comercial da árvore. O gráfico da Figura 1 evidencia o perfil do fuste observado no povoamento, correlacionando a razão entre diâmetro da posição e diâmetro a altura do peito ( $d$ /dap) e a razão entre posição e a altura total $(h / H t)$. 


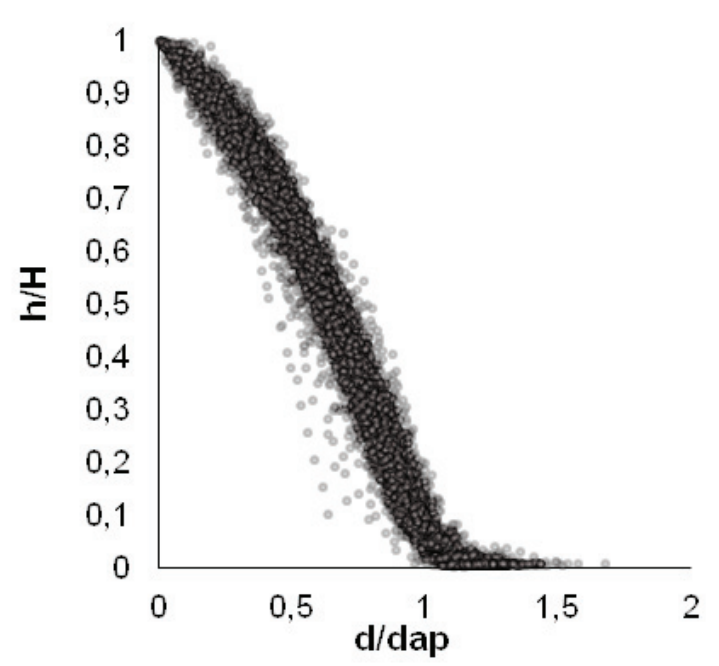

Figura 1. Gráfico de perfil do fuste de todas as árvores amostradas.

\section{Redes neurais artificiais}

As redes neurais artificiais (RNA) são sistemas computacionais paralelos constituídos por unidades de processamento simples, também denominadas neurônios artificiais ou nodos, conectadas entre si de uma maneira específica para desempenhar uma determinada tarefa (Binoti, 2010). Os neurônios artificiais são modelos matemáticos simplificados dos neurônios biológicos que processam as informações recebidas, ponderadas por pesos sinápticos, fornecendo uma única resposta (Haykin, 2001; Braga et al., 2007).

Em alguns casos, as RNA têm apresentado desempenho superior aos modelos de regressão devido a diversos fatores, como: estrutura maciça e paralelamente distribuída (camadas); habilidade de aprender e generalizar, que as tornam capazes de resolver problemas complexos; tolerância a falhas e ruídos; capacidade de modelar diversas variáveis e suas relações não-lineares; capacidade de modelagem com variáveis categóricas (qualitativas), além das numéricas (quantitativas); e analogia neurobiológica (Haykin, 2001; Bullinaria, 2010).

O treinamento das RNA foi realizado visando estimar o diâmetro (cm) ao longo do fuste (saída), utilizando como variáveis de entrada qualitativas o gênero (duas variáveis categóricas), a espécie (cinco variáveis categóricas) e a rotação atual (duas variáveis categóricas). As variáveis quantitativas foram o diâmetro medido a 1,30 $\mathrm{m}$ de altura da superfície do solo (dap, $\mathrm{em} \mathrm{cm}$ ), altura em que foram coletados os diâmetros ao longo do fuste $(\mathrm{m})$, altura total das árvores (m), idade (meses) e número de árvores por ha.

As estatísticas descritivas das variáveis quantitativas por estrato estão apresentadas na Tabela 3. A estratificação da base gerou nove estratos, buscando-se agrupar os dados de características mais homogêneas de acordo com gênero, espécie, rotação, espaçamento e classe de idade.

Para treinamento das RNA utilizou-se o sistema livre NeuroForest, versão 3.0. (NeuroForest, 2013)

As variáveis contínuas foram normalizadas linearmente no intervalo de 0 a 1 e as variáveis categóricas foram normalizadas utilizando-se a metodologia 1-de-N (Goldschmidt \& Passos, 2005; Heaton, 2011).

O número de neurônios na camada de entrada variou de acordo com o tipo da variável (qualitativa ou quantitativa) e o número de variáveis de entrada. Considerou-se um neurônio para cada variável quantitativa e um neurônio para cada classe de cada variável qualitativa. O número de neurônios na camada oculta variou entre 4 e 16 (com incremento a cada dois neurônios). A camada de saída foi constituída por um neurônio, sendo este referente ao diâmetro estimado para a altura $h$. Como funções de ativação da camada oculta e de saída foram testadas a função tangente hiperbólica, logística e sigmoide. Além disso, foram testadas as RNA do tipo Multilayer Perceptron (MLP) e os algoritmos de treinamento error backpropagation e resilient propagation (Haykin, 2001). Para o algoritmo error backpropagation, foram analisadas variações no valor da taxa de aprendizado $(0,001$ e 0,0001$)$ e no parâmetro momentum $(0,005$ e 0,0005$)$. Além das variações testadas, foram analisadas as estratégias de auto ajuste destes parâmetros, nos quais o processo reduz os valores dos parâmetros ao longo da evolução do algoritmo. Para o algoritmo resilient propagation foi utilizada a variação RPROP+ (Heaton, 2011).

Como critério de parada dos treinamentos das RNA foi utilizado o número total de 15.000 ciclos ou erro quadrático médio inferior a $0,1 \%$. Os pesos iniciais de todas as redes foram gerados de forma aleatória. Para cada combinação avaliada foram treinadas cinco redes, sendo selecionada a melhor destas, com base nos critérios de avaliação, para posterior comparação entre as combinações. 
Tabela 3. Estatísticas descritivas das variáveis contínuas amostradas e utilizadas para treinamento das redes neurais.

\begin{tabular}{|c|c|c|c|c|c|c|c|c|c|c|c|c|}
\hline \multirow{2}{*}{ Variável } & \multirow{2}{*}{ Estrato } & \multicolumn{4}{|c|}{ Estatísticas descritivas } & \multirow[b]{2}{*}{$\begin{array}{l}\text { Desv. } \\
\text { pad. }\end{array}$} & \multirow{2}{*}{ Estrato } & \multicolumn{4}{|c|}{ Estatísticas descritivas } & \multirow[b]{2}{*}{$\begin{array}{l}\text { Desv } \\
\text { pad. }\end{array}$} \\
\hline & & Mínimo & Máximo & Média & Mediana & & & Mínimo & Máximo & Média & Mediana & \\
\hline Idade (meses) & \multirow{6}{*}{1} & 6,42 & 6,42 & 6,42 & 6,42 & 0,00 & \multirow{6}{*}{6} & 3,67 & 3,67 & 3,67 & 3,67 & 0,00 \\
\hline dap $(\mathrm{cm})$ & & 6,00 & 20,50 & 14,63 & 14,30 & 4,04 & & 4,15 & 17,60 & 11,26 & 11,80 & 3,71 \\
\hline $\mathrm{N}\left(\operatorname{arv} \mathrm{ha}^{-1}\right)$ & & 1116,07 & 1116,07 & 1116,07 & 1116,07 & 0,00 & & 1666,67 & 1666,67 & 1666,67 & 1666,67 & 0,00 \\
\hline $\mathrm{Ht}(\mathrm{m})$ & & 11,10 & 29,10 & 21,97 & 22,10 & 4,93 & & 9,40 & 21,90 & 16,94 & 17,40 & 2,97 \\
\hline $\mathrm{h}(\mathrm{m})$ & & 0,10 & 25,00 & 8,76 & 8,00 & 6,16 & & 0,10 & 21,00 & 7,32 & 7,00 & 5,46 \\
\hline $\mathrm{d}(\mathrm{cm})$ & & 3,50 & 24,40 & 10,17 & 9,50 & 4,35 & & 1,00 & 20,45 & 7,79 & 7,15 & 4,25 \\
\hline Idade (meses) & \multirow{6}{*}{2} & 5,42 & 6,92 & 6,84 & 6,92 & 0,25 & \multirow{6}{*}{7} & 3,42 & 3,42 & 3,42 & 3,42 & 0,00 \\
\hline dap (cm) & & 6,78 & 21,17 & 14,81 & 15,60 & 4,42 & & 4,10 & 13,60 & 9,45 & 9,55 & 2,78 \\
\hline $\mathrm{N}\left(\operatorname{arv} \mathrm{ha}^{-1}\right)$ & & 1116,07 & 1116,07 & 1116,07 & 1116,07 & 0,00 & & 1111,11 & 1111,11 & 1111,11 & 1111,11 & 0,00 \\
\hline $\mathrm{Ht}(\mathrm{m})$ & & 13,73 & 29,02 & 23,93 & 25,48 & 4,30 & & 9,20 & 18,90 & 14,96 & 15,10 & 2,29 \\
\hline $\mathrm{h}(\mathrm{m})$ & & 0,10 & 28,00 & 10,66 & 10,00 & 7,67 & & 0,10 & 18,00 & 6,30 & 6,00 & 4,70 \\
\hline $\mathrm{d}(\mathrm{cm})$ & & 0,55 & 27,45 & 10,03 & 9,60 & 5,21 & & 1,00 & 18,85 & 6,77 & 6,30 & 3,42 \\
\hline Idade (meses) & \multirow{6}{*}{3} & 3,33 & 3,92 & 3,70 & 3,83 & 0,19 & \multirow{6}{*}{8} & 7,67 & 8,42 & 7,75 & 7,67 & 0,20 \\
\hline dap $(\mathrm{cm})$ & & 4,10 & 17,41 & 10,73 & 9,45 & 4,56 & & 7,48 & 24,13 & 17,57 & 18,94 & 4,73 \\
\hline $\mathrm{N}\left(\operatorname{arv~ha}^{-1}\right)$ & & 1754,39 & 1754,39 & 1754,39 & 1754,39 & 0,00 & & 1661,13 & 1661,13 & 1661,13 & 1661,13 & 0,00 \\
\hline $\mathrm{Ht}(\mathrm{m})$ & & 8,40 & 24,36 & 17,65 & 16,90 & 4,87 & & 10,00 & 18,90 & 15,99 & 16,76 & 2,25 \\
\hline $\mathrm{h}(\mathrm{m})$ & & 0,10 & 24,00 & 7,51 & 6,60 & 6,11 & & 0,10 & 18,00 & 6,94 & 7,00 & 5,14 \\
\hline $\mathrm{d}(\mathrm{cm})$ & & 0,10 & 21,05 & 7,41 & 6,55 & 4,38 & & 0,80 & 29,40 & 11,47 & 11,10 & 6,44 \\
\hline Idade (meses) & \multirow{6}{*}{4} & 3,60 & 4,13 & 3,93 & 4,13 & 0,24 & \multirow{6}{*}{9} & 7,58 & 8,67 & 8,07 & 7,58 & 0,54 \\
\hline dap (cm) & & 4,15 & 16,55 & 9,76 & 8,75 & 3,72 & & 6,68 & 24,51 & 17,47 & 18,84 & 4,75 \\
\hline$N\left(\operatorname{arv~ha}^{-1}\right)$ & & 1666,67 & 1666,67 & 1666,67 & 1666,67 & 0,00 & & 1661,13 & 1661,13 & 1661,13 & 1661,13 & 0,00 \\
\hline $\mathrm{Ht}(\mathrm{m})$ & & 9,70 & 23,40 & 17,18 & 16,50 & 4,19 & & 10,92 & 20,30 & 16,83 & 16,70 & 2,20 \\
\hline $\mathrm{h}(\mathrm{m})$ & & 0,10 & 23,00 & 7,38 & 7,00 & 5,76 & & 0,10 & 20,00 & 7,36 & 7,00 & 5,42 \\
\hline $\mathrm{d}(\mathrm{cm})$ & & 0,30 & 22,30 & 6,77 & 6,05 & 3,89 & & 0,50 & 29,80 & 11,60 & 11,10 & 6,58 \\
\hline Idade (meses) & \multirow{6}{*}{5} & 3,58 & 3,58 & 3,58 & 3,58 & 0,00 & & & & & & \\
\hline dap (cm) & & 4,10 & 18,00 & 12,30 & 13,45 & 3,97 & & & & & & \\
\hline $\mathrm{N}\left(\operatorname{arv~ha}^{-1}\right)$ & & 1754,39 & 1754,39 & 1754,39 & 1754,39 & 0,00 & & & & & & \\
\hline $\mathrm{Ht}(\mathrm{m})$ & & 9,40 & 19,50 & 16,25 & 16,80 & 2,70 & & & & & & \\
\hline $\mathrm{h}(\mathrm{m})$ & & 0,10 & 18,00 & 7,08 & 7,00 & 5,23 & & & & & & \\
\hline $\mathrm{d}(\mathrm{cm})$ & & 1,00 & 22,45 & 8,32 & 7,55 & 4,68 & & & & & & \\
\hline
\end{tabular}

Em que: dap = diâmetro medido a $1,30 \mathrm{~m}$ de altura $(\mathrm{cm}) ; \mathrm{N}=$ número de árvores por ha; $\mathrm{Ht}=$ altura total das árvores $(\mathrm{m}) ; \mathrm{h}=$ altura em que foram coletados os diâmetros ao longo do fuste $(\mathrm{m}) \mathrm{e}$; $\mathrm{d}$ = diâmetro coletado ao longo do fuste (cm).

Com o intuito de se comparar alguns modelos de regressão comumente utilizados pelas empresas brasileiras para descrição do perfil do fuste em plantios comerciais com as redes neurais, foram selecionados os seguintes modelos: a) Kozak et al. (1969)

$\left(\frac{\mathrm{d}}{d a p}\right)^{2}=\beta_{1}+\beta_{2}\left(\frac{h}{H t}\right)+\beta_{3}\left(\frac{h}{H t}\right)^{2}+\varepsilon$ 
b) Demaerschalk (1972)

$\left(\frac{\mathrm{d}}{d a p}\right)^{2}=10^{\left(2 \beta_{0}\right)} d a p^{\left(2 \beta_{1}-2\right)} H t^{\left(2 \beta_{2}\right)}(H t-h)^{\left(2 \beta_{3}\right)}+\varepsilon(2)$

c) Ormerod (1973)

$\frac{\mathrm{d}}{d a p}=\left(\frac{H t-h}{H t-1,3}\right)^{\beta_{3}}+\varepsilon$

d) Garay (1979)

$\frac{\mathrm{d}}{d a p}=\beta_{0}\left(1+\beta_{1} \ln \left(1-\beta_{2} h^{\beta_{3}} H t^{-\beta_{3}}\right)\right)+\varepsilon$

Em que: $d=$ diâmetro observado na altura $h(\mathrm{~cm}) ; d a p=$ diâmetro a $1,30 \mathrm{~m}(\mathrm{~cm}) ; \beta \mathrm{i}=$ parâmetro a ser estimado $(\mathrm{i}=0$, $1,2$ e 3$) ; \varepsilon=$ erro aleatório; $h=$ altura em que foram coletados os diâmetros ao longo dos fustes (m); e Ht = altura total (m).

\section{Avaliação das estimativas das redes neurais artificiais e do modelo de regressão}

A avaliação das redes neurais artificiais, bem como dos modelos de afilamento, foi realizada com base nas estatísticas:

a) Coeficiente de correlação entre os diâmetros observados e estimados

$$
r_{y y}=\frac{\operatorname{cov}\left(\hat{Y}_{i}, Y_{i}\right)}{\sqrt{S^{2}\left(\hat{Y}_{i}\right) S^{2}\left(Y_{i}\right)}}
$$

em que: $s^{2}=$ variância e $c o v=$ covariância.

b) raiz quadrada do erro médio (RMSE - Root Mean Square Error)

$$
\operatorname{RMSE}(\%)=\frac{100}{\bar{Y}} \sqrt{\frac{\sum_{i=1}^{n}\left(Y_{i}-\hat{Y_{i}}\right)^{2}}{n}}
$$

Em que: $\bar{Y}:$ média dos diâmetros observados e $\mathrm{N}=$ número total de árvores.

Além destas estatísticas, foi realizada a análise gráfica da dispersão dos erros percentuais em função do dap e do histograma de frequência percentual dos erros percentuais.
$\operatorname{erro}(\%)=\frac{Y_{i}-Y_{i}}{Y_{i}} .100$

Em que: $\mathrm{Y}_{\mathrm{i}}=$ diâmetro observado na altura $\mathrm{h}$ da i-ésima árvore e $\hat{Y}_{\mathrm{i}}=$ diâmetro estimado na altura $\mathrm{h}$ da i-ésima árvore.

Foi escolhida a RNA que apresentou maior coeficiente de correlação e menor RMSE, e gráficos de dispersão sem tendenciosidade e histogramas com maior ocorrência de estimativas em torno de zero.

\section{Resultados e discussão}

Foram ajustadas nove equações, uma para cada estrato, para cada modelo de afilamento avaliado (Tabela 4), sendo que o modelo de Garay foi o que apresentou os melhores resultados em termos de acurácia, isto é, maior coeficiente de correlação entre os diâmetros observados ao longo do fuste e os diâmetros estimados, melhor dispersão dos resíduos e histograma de frequência dos resíduos, indicando maior proximidade dos valores observados e estimados. Salienta-se que os modelos de Demaerschalk e Ormerod não obtiveram ajustes satisfatórios em descrever o perfil do fuste para os dados utilizados.

Tabela 4. Parâmetros das equações dos modelos de afilamento de Garay ajustados para cada estrato.

\begin{tabular}{ccccc}
\hline \multirow{2}{*}{ Estrato } & \multicolumn{4}{c}{ Parâmetros } \\
\cline { 2 - 5 } & $\beta_{0}$ & $\beta_{1}$ & $\beta_{2}$ & $\beta_{3}$ \\
\hline 1 & 1,4126 & 0,2564 & 0,9865 & 0,1417 \\
2 & 1,4462 & 0,2034 & 0,9927 & 0,0859 \\
3 & 1,3638 & 0,2664 & 0,9781 & 0,1798 \\
4 & 1,5709 & 0,2150 & 0,9909 & 0,0783 \\
5 & 1,5063 & 0,2455 & 0,9839 & 0,1109 \\
6 & 1,3299 & 0,2837 & 0,9724 & 0,2114 \\
7 & 1,6503 & 0,1842 & 0,9967 & 0,0523 \\
8 & 1,2543 & 0,3686 & 0,9310 & 0,2954 \\
9 & 1,5490 & 0,2318 & 0,9875 & 0,0906 \\
\hline
\end{tabular}

Na Figura 2 são expostos os gráficos de dispersão dos resíduos e histograma de frequência dos resíduos. $\mathrm{Na}$ Tabela 5 são apresentadas as estatísticas da rede neural artificial (RNA) e do modelo de afilamento selecionado com melhor capacidade de estimar os diâmetros ao longo dos fustes de árvores de pinus e eucalipto. 


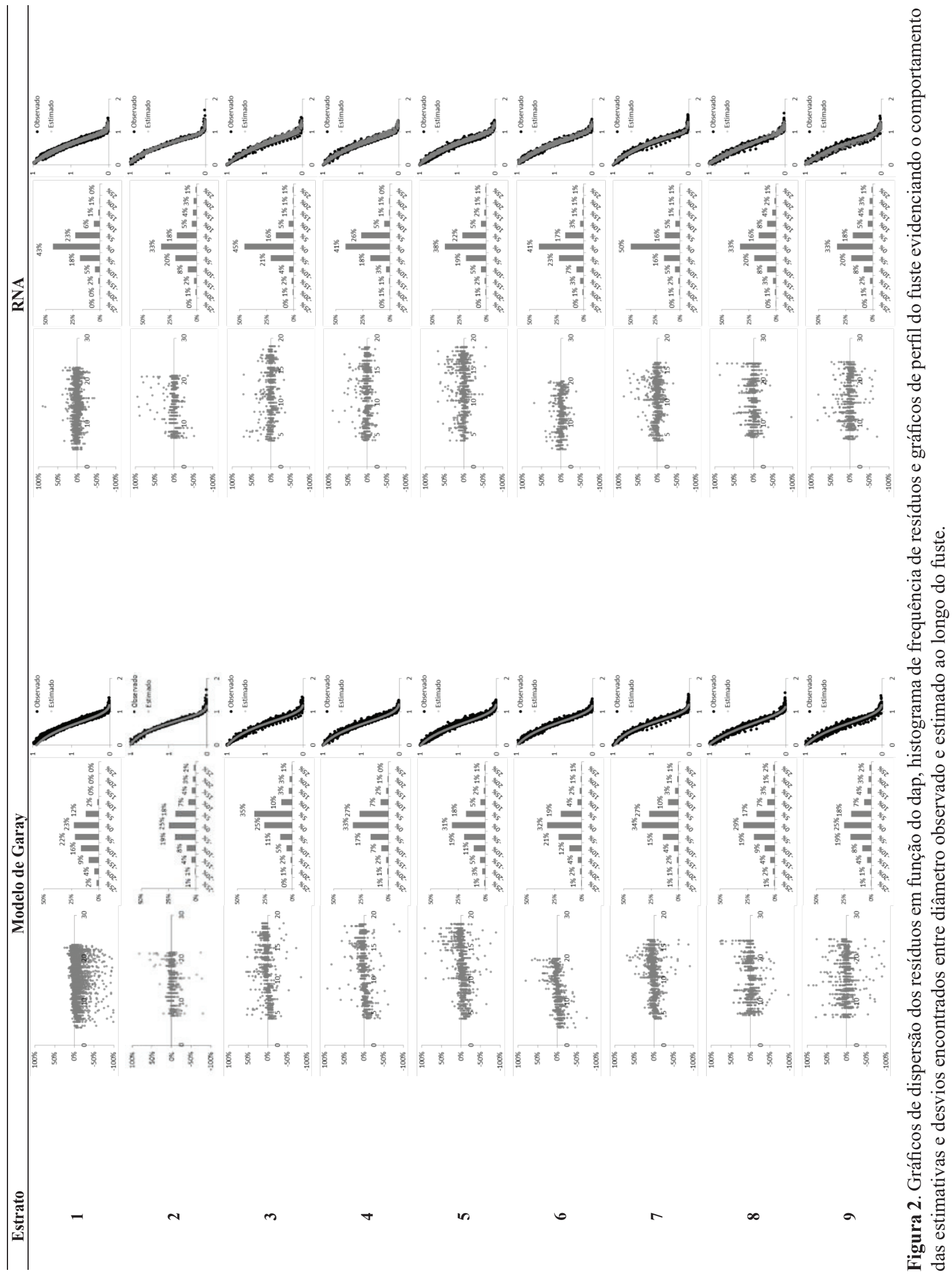


Tabela 5. Estatísticas dos ajustes do modelo de afilamento e das rede neurais artificais (RNA), bem como descrições das configurações das RNA selecionadas.

\begin{tabular}{|c|c|c|c|c|c|c|c|c|c|c|c|}
\hline & \multirow{2}{*}{ Estatísticas } & \multicolumn{10}{|c|}{ Estratos } \\
\hline & & 1 & 2 & 3 & 4 & 5 & 6 & 7 & 8 & 9 & Geral \\
\hline \multirow{2}{*}{ Garay } & $\mathrm{r}_{\hat{Y} y}(\%)$ & 99,0 & 99,1 & 99,5 & 99,6 & 99,4 & 99,5 & 99,1 & 99,2 & 99,1 & 99,1 \\
\hline & RMSE (\%) & 9,6 & 7,1 & 6,9 & 6,0 & 6,3 & 6,1 & 7,2 & 7,4 & 7,9 & 7,9 \\
\hline \multirow{2}{*}{ RNA } & $\mathrm{r}_{\hat{\mathrm{Y} y}}(\%)$ & 99,5 & 99,5 & 99,7 & 99,7 & 99,6 & 99,6 & 99,4 & 99,4 & 99,4 & 99,5 \\
\hline & RMSE (\%) & 4,6 & 5,4 & 4,6 & 4,1 & 5,2 & 5,2 & 5,8 & 6,4 & 6,6 & 5,3 \\
\hline
\end{tabular}

Com base nas estatísticas utilizadas para análise do desempenho dos modelos e os gráficos utilizados para análise visual do ajuste, o modelo de regressão de Garay obteve melhor desempenho em descrever o perfil do fuste, com $=99,1 \%$ e RMSE $=7,9 \%$. Ao analisar os gráficos por estrato, pode-se notar que o modelo de Garay mostrou-se ligeiramente tendencioso em estimar os diâmetros ao longo do fuste para alguns estratos.

Ao analisar as estatísticas referentes aos diâmetros ao longo dos fustes estimados pela RNA selecionada, pode-se notar $=99,5 \%$ e RMSE $=5,3 \%$, com gráficos de dispersão de resíduos e histogramas de resíduos não tendenciosos, com capacidade de descrever o perfil do fuste de forma fidedigna.

Observam-se resultados satisfatórios em configurações de apenas seis ou oito neurônios na camada oculta, evidenciando que não são necessárias estruturas complexas para estimação do diâmetro ao longo do fuste. Isso pode estar relacionado ao número de neurônios na camada oculta, ligado à representação da não linearidade entre os dados (Binoti, 2012) e, para este caso, não houve necessidade de grande complexidade da estrutura da rede para extrair a relação entre as variáveis utilizadas e o perfil do fuste.

Recomendam-se configurações mais simples para essa aplicação das RNA, evitando ocorrência de overfitting e facilitando o processo de busca e otimização da configuração para determinada tarefa (Braga et al., 2007; Bullinaria, 2010).

O algoritmo error backpropagation obteve desempenho inferior ao algoritmo Resillient propagation para estimar o diâmetro ao longo do fuste.

As três funções de ativação testadas (tangente hiperbólica, logística e sigmoidal) apresentaram resultados satisfatórios para estimação do diâmetro ao longo do fuste, tanto na camada oculta quanto na camada de saída. Notou-se que, em alguns casos, ao utilizar a função tangente hiperbólica na camada de saída, a RNA estimou volumes negativos.

Para o algoritmo error backpropagation, o melhor desempenho foi encontrado para a configuração dos parâmetros taxa de aprendizagem e momentum em 0,0001 e 0,0005 , respectivamente, e quando se utilizou a estratégia de auto ajuste.

As estimativas obtidas por meio das equações de regressão ajustadas foram baseadas em nove equações de afilamento para cada modelo, sendo uma para cada estrato. Esta estratificação requer maior quantidade de amostras para cada estrato, a fim de se obter ajustes satisfatórios das equações, o que nem sempre ocorre.

\section{Conclusões}

Os métodos de inteligência artificial, especialmente rede neural artificial (RNA), podem ser eficazes em descrever o perfil do fuste de árvores de diferentes espécies em diferentes condições de crescimento, utilizando apenas uma RNA, com eficiência semelhante aos modelos de regressão tradicionalmente empregados por empresas florestais.

\section{Referências}

Assis, A. L. et al. Comparação de modelos polinomiais segmentados e não-segmentados na estimativa de diâmetros e volumes ao longo do fuste de Pinus taeda. Cerne, v. 7, n. 1, p. 20-40, 2001.

Baldwin Júnior, V. C. \& Feduccia, D. P. Compatible tree-volume and upper-stem diameter equations for plantation Loblolly Pines in the West Gulf region. South. Journal Applied Forestry, v. 15, n. 2, p. 92-97, 1991.

Bertolotti, G. et al. Efeitos de diferentes métodos e intensidades de desbaste na produtividade de Pinus caribaea var. hondurensis Barr. et Golf. IPEF, v. 24, p. 47-54, 1983.

Binoti, D. H. B. et al. Configuração de redes neurais artificiais para estimação do volume de árvores. Ciência da Madeira, v. 5, n. 1, p. 58-67, 2014. 
Binoti, D. H. B. et al. Modelagem da distribuição de diâmetros utilizando autômatos celulares e redes neurais artificiais. Cerne, v. 19, n. 4, p. 677-685, 2013a.

Binoti, D. H. B. et al. Modelagem da distribuição diamétrica em povoamentos de Eucalipto submetidos a desbaste utilizando autômatos celulares. Revista Árvore, v. 36, n. 5, p. 931-940, 2012. DOI: $10.1590 / \mathrm{S} 0100-67622012000500015$.

Binoti, D. H. B. et al. Redução dos custos em inventário de povoamentos equiâneos. Agrária: Revista Brasileira de Ciências Agrárias, v. 8, n. 1, p. 125-129, 2013b. DOI: 10.5039/agraria. v8i1a2209.

Binoti, D. H. B. et al. Uso da função Weibull de três parâmetros em um modelo de distribuição diamétrica para plantios de eucalipto submetidos a desbaste. Revista Árvore, v. 34, p. 147-156, 2010. DOI: $10.1590 / \mathrm{S} 0100-67622010000100016$.

Binoti, M. L. M. da S. Emprego de redes neurais artificiais em mensuração e manejo florestal. 2012. 130 f. Tese (Doutorado em Ciência Florestal) - Universidade Federal de Viçosa, Viçosa, MG.

Binoti, M. L. M. da S. Redes neurais artificiais para prognose da produção de povoamentos não desbastados de Eucalipto. 2010. 54 f. Dissertação (Mestrado em Ciência Florestal) - Universidade Federal de Viçosa, Viçosa, MG.

Braga, A. P. et al. Redes neurais artificiais: teoria e aplicação. Rio de Janeiro: LTC, 2007. 262 p.

Bullinaria, J. A. Introduction to neural computation. Notas de aula. Disponível em: <http://www.cs.bham.ac.uk/ jxb/inc.html >. Acesso em: 21 mar. 2010.

Campos, B. P. F. et al. Conversão de árvores em multiprodutos da madeira utilizando programação inteira. Revista Árvore, v. 37, n. 5, p. 881-887, 2013. DOI: 10.1590/S0100-67622013000500010.

Campos, J. C. C. Análise de crescimento e produção em plantações desbastadas. Revista Árvore, v. 4, n. 2, p. 157-169, 1980.

Demaerschalk, J. P. Integrated systems for the estimation of tree taper and volume. Canadian Journal Forest Research, v. 3, n. 90, p. 90-94, 1972.

Diamantopoulou, M. J. Artificial neural networks as an alternative tool in pine bark volume estimation. Computers and Electronics in Agriculture, v. 48, n. 3, p. 235-244, 2005a. DOI: 10.1016/j. compag.2005.04.002.

Diamantopoulou, M. J. Predicting fir trees stem diameters using artificial neural network models. Southern African Forestry Journal, v. 205, n. 1, p. 39-44, 2005b. DOI: 10.2989/10295920509505236.

Diamantopoulou, M. J. Tree-bole volume estimation on standing pine trees using cascade correlation artificial neural network models. Agricultural Engineering International: The CIGR EJournal, v. 8, 2006.

Diamantopoulou, M. \& Milios, E. Modelling total volume of dominant pine trees in reforestations via multivariate analysis and artificial neural network models. Biosystems Engineering, v. 105, p. 306-315, 2010. DOI: 10.1016/j.biosystemseng.2009.11.010.

Pesq. flor. bras., Colombo, v. 37, n. 90, p. 99-107, abr.jun. 2017
Dias, A. N. Um modelo para gerenciamento de plantações de eucalipto submetidas a desbaste. 2005. $135 \mathrm{f}$. Tese (Doutorado Ciência Florestal) - Universidade Federal de Viçosa, Viçosa, MG.

Fischer, F. et al. Exatidão dos modelos polinomiais não-segmentados e das razões entre volumes para representar o perfil do tronco de Pinus taeda. Ciência Florestal, v. 11, n. 1, p. 167-188, 2001.

Garay, L. Tropical forest utilization system: VIII. A taper model for entire stem profile including buttressing. Seattle: College of Forest Resources, University of Washington, 1979. 64 p. (Contribution, 36).

Garcia, S. L. R. et al. Análise do perfil do tronco de morototó (Didymopamax morototonii) em função do espaçamento. In: CONGRESSO FLORESTAL PANAMERICANO, 1., CONGRESSO FLORESTAL BRASILEIRO, 7., 1993, Curitiba. Anais... Curitiba: SBS/SBEF, 1993. p. 485-491.

Goldschmidt, R. R. \& Passos, E. Data mining: um guia prático. Rio de Janeiro: Campos, 2005. 261 p.

Görgens, E. B. et al. Estimação do volume de árvores utilizando redes neurais artificiais. Revista Árvore, v. 33, n. 6, p. 1141-1147, 2009. DOI: 10.1590/S0100-67622009000600016.

Görgens, E. B. et al. Influência da arquitetura na estimativa de volume de árvores individuais por meio de redes neurais artificiais. Revista Árvore, v. 38, n. 2, p. 289-295, 2014. DOI: 10.1590/S010067622014000200009.

Haykin, S. Redes neurais: princípios e prática. Porto Alegre, 2001. $900 \mathrm{p}$.

Heaton, J. Programming neural networks with Encog3 in Java. 2nd ed. Heaton Research, Inc. 2011. 226 p.

Kozak, A. et al. Taper functions and their applications in forest inventory. Forest Chronicle, v. 45, n. 4, p. 278-283, 1969.

Leduc, D. J. et al. Predicting diameter distributions of longleaf pine plantations. Asheville: U.S. Dept. of Agriculture, Forest Service, Southern Research Station, 2001. 18 p. (Research paper).

Leite, H. G. et al. Avaliação do ajuste das funções Weibull e hiperbólica a dados de povoamentos de eucalipto submetidos a desbaste. Revista Árvore, v. 34, n. 2, p. 305-311, 2010.

Leite, H. G. et al. Estimation of inside-bark diameter and heartwood diameter for Tectona grandis Linn. trees using artificial neural networks. European Journal of Forest Research, v. 130, n. 2, p. 263-269, 2011. DOI: 10.1007/s10342-010-0427-7.

Leite, H. G. \& Garcia, S. L. R. Pesquisa e desenvolvimentos em inventário, mensurações e manejo florestal na CENIBRA. Viçosa, MG: Sociedade de Investigações Florestais, 2001. 49 p. (Relatório Técnico, SIF).

Max, T. A. \& Burkhart, H. E. Segmented polynomial regression applied to taper equations. Forest Science, v. 22, n. 2, p. 283-289, 1976.

Mendonça, A. R. de et al. Avaliação de funções de afilamento visando a otimização de fustes de Eucalyptus spp. para multiprodutos. Cerne, v. 13, n. 1, p. 71-82, 2007.

Môra, R. et al. Análise de diferentes formas de ajuste de funções de afilamento. Scientia Forestalis, v. 42, n. 102, p. 237-249, 2014. 
Neuroforest: versão: 3.0. Viçosa, MG, [2013]. Desenvolvido pelo projeto NeuroForest, DAP Engenharia Florestal e os professores Helio Garcia Leite (UFV) e Mayra Luiza M S Binoti (UFVJM).

Nogueira, G. S. et al. Determinação da idade técnica de desbaste em plantações de eucalipto utilizando o método dos ingressos percentuais. Scientia Forestalis, n. 59, p. 51-59, 2001.

Nogueira, G. S. Modelagem do crescimento e da produção de povoamentos de Eucalyptus spp. e de Tectona grandis submetidas a desbaste. 2003. 126 f. Tese (Doutorado em Ciência Florestal) Universidade Federal de Viçosa, MG.

Ormerod, D. W. A simple bole model. Forest Chronicle, v. 49, n. 3, p. 136-138, 1973.

Pires, L. M. \& Calegario, N. Ajuste de modelos estocásticos lineares e não-lineares para a descrição do perfil longitudinal de árvores. Revista Árvore, v. 31, n. 5, p. 845-852, 2007. DOI: 10.1590/S010067622007000500008 .

Silva, J. C. da. Aspectos econômicos do desbaste em reflorestamento no Norte do Paraná. Floresta, v. 2, n. 3, p. 13-18, 1970.
Silva, M. L. M. et al. Ajuste do modelo de Schumacher e Hall e aplicações de redes neurais artificiais para estimar volume de árvores de Eucalipto. Revista Árvore, v. 33, n. 6, p. 1133-1139, 2009. DOI: 10.1590/S0100-67622009000600015.

Soares, F. A. A. M. N. et al. Recursive diameter prediction for calculating merchantable volume of Eucalyptus clones without previous knowledge of total tree height using artificial neural networks. Applied Soft Computing, v. 12, p. 2030-2039, 2012. DOI: 10.1016/j.asoc.2012.02.018.

Soares, R. V. Desbastes em Araucaria angustifolia (Bert) O'Ktze. Floresta, v. 2, n. 3, p. 59-67, 1970.

Souza, C. A. M. et al. Modelos de afilamento para o sortimento do fuste de Pinus taeda L. Ciência Rural, v. 38, n. 9, p. 2506-2511, 2008. DOI: 10.1590/S0103-84782008000900014.

Souza, C. A. M. Modelos de afilamento para Pinus taeda $\mathbf{L}$. ajustados segundo a forma do tronco e métodos de estratificação. 2009. 120 f. Tese. (Doutorado em Engenharia Florestal) Universidade Federal de Santa Maria, Santa Maria, RS. 
